\title{
Research of Nitrogen Oxides Concentrations in Exhaust Gas of Compression Ignition Engine Fuelled with Alternative Fuel
}

\author{
Mieczysław Sikora ${ }^{1 *}$, Piotr Orliński ${ }^{1}$, Mateusz Bednarski ${ }^{1}$ \\ 1 Faculty of Automotive and Construction Machinery Engineering, Warsaw University of Technology, ul. \\ Narbutta 84, 02-524 Warsaw, Poland \\ * Corresponding author's email: mieczyslaw.sikora@pw.edu.pl
}

\begin{abstract}
The research was divided into two stages. The first stage of work was to perform empirical research using the Perkins engine. The test stand was equipped with an exhaust gas composition analyzer, a pressure sensor enabling measurement of pressure in the engine cylinder and a crankshaft position sensor. This stage of research was realized for diesel and UCOME fuel. The second stage was a simulation test. The Zeldovich model of thermal NO formation in compression ignition engines was used for calculations. Theoretical methods were compared with the results obtained in empirical tests. It was found that the most similar results of tests when powering the engine with UCOME fuel were obtained thanks to the GRI-MECH $3.0(\mathrm{G})$ method. On the basis of this method, coefficients of the reaction rate of $\mathrm{NO}$ formation in an internal combustion engine, which is powered by the higher generation alternative fuel (Sikora et al. (S) method) were developed. For the calculation tests the values of the experimentally determined pressures were used. The proposed method can be used in simulation tests of a diesel engine running on FAME fuels with similar physical and chemical properties as the UCOME fuel. This will significantly reduce the costs of such tests, as some empirical tests can be eliminated by the conclusions of the simulation tests.
\end{abstract}

Keywords: oxides of nitrogen; internal combustion engines; speed coefficients for chemistry reaction; alternative fuel

\section{INTRODUCTION}

Because of the worsening environmental conditions, people have paid more and more attention to the impact of their activities on it. For many years, more and more intensive activities have been undertaken to protect the natural environment of people around the world. The automotive industry is one of the working areas which has been stressed. The road transport is the second-largest economic sector responsible for about $20 \%$ of emissions of harmful substances and greenhouse gases to the atmosphere [1-4]. Makers of the modern engines should figure out for many technical difficulties to come in for effective parameters as well as keeping low costs of production. Simultaneously constructors have regard to low emission of toxic substances $[5,6]$. Directive of the European Parliament and of the Council for the promotion and using the energy from renewable sources set out directions for the reduction of toxic components emissions [7]. One of the directions to reduce the emission of toxic exhaust components is the use of second-generation FAME fuels [8]. This fuel group includes UCOME fuels. These are fuels made from animal waste, fatty acids and burned vegetable oils [911]. In order to reach appropriate demands, it is essential to use the system which optimally uses the potential of the structure to gain the output parameters [12-15]. One of the substances harmful to health is NOx. These are contained in the engine exhaust gas and they are covered by European regulation regulations are NOx. For this reason, simulation studies of theoretical methods for the determination of NOx concentrations in a diesel engine are so important. Nitrogen oxides (NOx) make a difference to the formation of ozone and a smog [16]. In the case of fuel combustion, a thermal mechanism of NO formation is 
used. This mechanism is known as the Zeldovich mechanism. The thermal mechanism of the formation of nitrogen oxides consists of their formation from nitrogen and atmospheric oxygen at high temperatures. The Zeldovich mechanism is most often used from all mechanisms of NO formation. Nevertheless, there is still doubtfulness regarding the selection of speeds constants [17]. For this reason, it is worth carrying out tests for various engines and various fuels to improve the model.

The aim of the research was to develop a theoretical method used to simulate the concentration of nitrogen oxides in the exhaust gas of a diesel engine powered by liquid alternative fuels. The method was developed based on previous research [17]. As a results of these tests the most advantageous method was selected for environmental reasons and the reaction rate coefficients of nitrogen oxides formation were developed, which very accurately imitate the real NO concentrations when the engine is powered with alternative fuels. The empirical and simulation studies were carried out for diesel oil and the fuel used cooking oil methyl esters (UCOME). Calculations results were based on a thermal NO formation by the Zeldovich mechanism for combustion engines.

One of the components of toxic engine exhaust is nitrogen oxides. They act destructively on the environment and this contributes to an ozone depletion phenomenon. If all the oxides of nitrogen are taken into consideration, $\mathrm{NO}$ and $\mathrm{NO}_{2}$ are mainly formed in the engine cylinders [18, 19]. For this reason, the authors dealt with NO in studies. Nitrogen oxides are formed in flame processes [23]. They arise from the oxidation of nitrogen contained in the air. Factors that favor oxidation of nitrogen to nitric oxide in the cylinder are high temperature and composition of the mixture [17]. The temperature in the cylinder depends on the used fuel. Therefore, it is important to study the concentration of nitrogen oxides for various fuels. The evolution of mechanisms of creating nitrogen oxides has taken place in the seventies of the last century. This was largely due to the evolution of computing possibilities, which shorten computational research. Based on the literature review, the basic mechanism for the formation of nitrogen oxides is the Zeldovich mechanism. The model assumes that at every moment the operating medium (the homogeneous mixture of air and combustion products) is in the state of thermodynamic equilibrium [17]. The reaction speed factors of mechanisms of NO formation in the internal combustion engine are based on the temperature in the cylinder of the engine $[22,24]$ and it is the reaction rate coefficients in this mechanism that were studied in the development of the new method by the authors of this paper (S). The literature review led to the conclusion that nitrogen oxide concentration tests were conducted for diesel fuel. However, the reaction rate coefficients used in Zeldovich mechanics need to be corrected when alternative fuels are tested.

\section{MATERIALS AND METHODS}

The first stage of the work consisted of performing empirical tests using the Perkins engine. The test stand made it possible to precisely control the engine and determine its operating conditions and torque. The system was equipped with an AVL CEB II exhaust gas analyzer, a pressure sensor (enabling measurement of engine cylinder pressure) and a crankshaft position sensor. Empirical tests were conducted for diesel and UCOME fuel. The second stage was simulation tests. On the basis of previously conducted tests, the authors noted that the most accurate method that can be used to test the concentrations of nitrogen oxides in the exhaust fumes of an engine is the $\mathrm{G}$ method. The G-method determines the reaction rate coefficients of the Zeldowich mechanism of nitrogen oxide generation. Table 1 shows the exact values of these coefficients. This method is commonly used in the case of diesel fuel supply. Taking the G method as a base point, a model of nitrogen oxide formation was proposed, but for an engine running on alternative fuel. Thanks to the empirical tests, it was possible to correct the model in such a way that the results of empirical tests show high accuracy with simulation tests. Appropriate values for reaction rates were proposed. The speed rates for the Zeldovich mechanism forward reaction are shown in Table 1. This has resulted in a new model of nitrogen oxide formation in a higher generation alternative fuel engine. The following table shows the changes in the $\mathrm{G}$ method and thus presents the new method proposed by the authors.

The Zeldovich mechanism was used in this thesis. This Zeldovich mechanism consists of three elementary reactions with experimentally determined speed constants $\mathrm{k}_{\mathrm{i}}$ [17]:

$$
\begin{aligned}
& O+\mathrm{N}_{2} \leftrightarrow \mathrm{NO}+\mathrm{N} \\
& N+O_{2} \leftrightarrow N O+O \\
& N+O H \leftrightarrow N O+H
\end{aligned}
$$


Table 1. Speed coefficients for the forward reaction of the Zeldovich mechanism [17]

\begin{tabular}{|c|c|l|}
\hline \multirow{2}{*}{ Reaction $i$} & $\mathrm{k}_{1, \mathrm{r}}\left[\frac{\mathrm{cm}}{\mathrm{mol} \mathrm{s}}\right]$ & \multicolumn{1}{|c|}{ Author } \\
\hline \multirow{2}{*}{1} & $0,544 \cdot 10^{14} T^{0,1} \exp \left[-\frac{38020}{T}\right]$ & GRI-MECH 3.0 (2000) \\
\cline { 2 - 3 } & $0,5 \cdot 10^{14} T^{0,1} \exp \left[-\frac{38555}{T}\right]$ & Sikora et al. (2021) \\
\hline \multirow{2}{*}{2} & $9 \cdot 10^{9} T \exp \left[-\frac{3280}{T}\right]$ & GRI-MECH 3.0 (2000) \\
\cline { 2 - 3 } & $10^{10} T \exp \left[-\frac{3310}{T}\right]$ & Sikora et al. (2021) \\
\hline \multirow{2}{*}{3} & $3,36 \cdot 10^{13} \exp \left[-\frac{195}{T}\right]$ & GRI-MECH 3.0 (2000) \\
\cline { 2 - 3 } & $3 \cdot 10^{13} \exp \left[-\frac{205}{T}\right]$ & Sikora et al. (2021) \\
\hline
\end{tabular}

Thermal NO formation proceeds were characterized by Zeldovich. This reaction mechanism was expanded by Baulch. The Zeldovich mechanism contains three elementary reactions. In the case of chemical equilibrium, the forward and reverse reactions advance equally fast [17]:

$$
\mathrm{k}_{1, \mathrm{r}}[\mathrm{O}]\left[\mathrm{N}_{2}\right]=\mathrm{k}_{1,1}[\mathrm{NO}][\mathrm{N}]
$$

or according to the appropriate reformulation [17]:

$$
\begin{gathered}
\frac{\mathrm{k}_{1, \mathrm{r}}}{\mathrm{k}_{1,1}}=\frac{[\mathrm{NO}][\mathrm{N}]}{[0]\left[\mathrm{N}_{2}\right]}=K_{C, 1} \\
K_{C, 1}=\frac{\mathrm{k}_{\mathrm{r}}}{\mathrm{k}_{\mathrm{l}}}
\end{gathered}
$$

Speed constants, and the equilibrium constant are dependent on temperature. We receive reaction equations [17]:

$$
\begin{gathered}
\frac{\mathrm{d}[\mathrm{NO}]}{\mathrm{dt}}=\mathrm{k}_{1, \mathrm{r}}[\mathrm{O}]\left[\mathrm{N}_{2}\right]+\mathrm{k}_{2, \mathrm{r}}[\mathrm{N}]\left[\mathrm{O}_{2}\right]+ \\
+\mathrm{k}_{3, \mathrm{r}}[\mathrm{N}][\mathrm{OH}]-\mathrm{k}_{1,1}[\mathrm{NO}][\mathrm{N}]- \\
-\mathrm{k}_{2,1}[\mathrm{NO}][\mathrm{O}]-\mathrm{k}_{3,1}[\mathrm{NO}][\mathrm{H}]
\end{gathered}
$$

and for the momentary change of nitrogen concentrations follows on [17]:

$$
\begin{gathered}
\frac{\mathrm{d}[\mathrm{N}]}{\mathrm{dt}}=\mathrm{k}_{1, \mathrm{r}}[\mathrm{O}]\left[\mathrm{N}_{2}\right]-\mathrm{k}_{2, \mathrm{r}}[\mathrm{N}]\left[\mathrm{O}_{2}\right]- \\
-\mathrm{k}_{3, \mathrm{r}}[\mathrm{N}][\mathrm{OH}]-\mathrm{k}_{1, \mathrm{l}}[\mathrm{NO}][\mathrm{N}]+ \\
+\mathrm{k}_{2, \mathrm{l}}[\mathrm{NO}][\mathrm{O}]+\mathrm{k}_{3, \mathrm{l}}[\mathrm{NO}][\mathrm{H}]
\end{gathered}
$$

The speed of reaction (1) is lower than the speed of reactions (2) and (3) by order of magnitude. The nitrogen is created in the first reaction. Then it is converted to NO. The intensity of atomic nitrogen is constant after the first phase. The intensity of [N] can be quasi-steady [17]:

$$
\frac{\mathrm{d}[\mathrm{N}]}{\mathrm{dt}}=0
$$

We get the following equations [17]:

$$
\frac{\mathrm{d}[\mathrm{NO}]}{\mathrm{dt}}=2 \mathrm{k}_{1, \mathrm{r}}[\mathrm{O}]\left[\mathrm{N}_{2}\right]-2 \mathrm{k}_{1, \mathrm{l}}[\mathrm{NO}][\mathrm{N}]
$$

Diesel oil (D) and the fuel used cooking oil methyl esters (UCOME) were used for calculations in studies. UCOME could be a substitute fuel for diesel oil because its physicochemical properties are similar. The physicochemical properties of the two fuels are presented in Table 2.

The data in the table show that the cetane number of diesel oil is about $8 \%$ higher than the cetane number of UCOME fuel. It should also be noted that the heating value of diesel oil is about 16\% higher than the heating value of UCOME. It is also seen that the kinematic viscosity of the UCOME is almost twice as high as the viscosity of the diesel oil.

The empirical and simulation studies were conducted for seven different engine speeds. Statistical analysis of the results allows us to determine the percentage differences in nitrogen oxide concentrations due to the chosen fuel and method.

Table 2. Selected properties of diesel oil and UCOME [25, 26]

\begin{tabular}{|l|c|c|c|}
\hline \multicolumn{1}{|c|}{ Properties } & UCOME & Diesel oil & Test methods \\
\hline Cetane number & 48.3 & 52.4 & PN-EN ISO 5165 \\
\hline Fuel value $[\mathrm{MJ} / \mathrm{kg}]$ & 38.6 & 43.2 & PN-86/C-04062 \\
\hline Kinematic viscosity $\left[\mathrm{mm}^{2} / \mathrm{s}\right](310 \mathrm{~K})$ & 4.73 & 2.64 & PN-EN ISO 3104 \\
\hline Density at temperature $288 \mathrm{~K}\left[\mathrm{~kg} / \mathrm{m}^{3}\right]$ & 885 & 835 & PN-EN ISO 12185 \\
\hline Ignition temperature $[\mathrm{K}]$ & 470 & 375 & PN-EN ISO 2719 \\
\hline
\end{tabular}




\section{RESULTS}

The results are shown in the diagrams below. The graphs show the concentration of NO at the same speed-load operating conditions of the engine. The experimental values of cylinder pressures were used for calculations in studies. The study has been carried out at two fuels: diesel oil and the fuel used cooking oil methyl esters (UCOME). The research was carried out on the basis of authors (S) method for determining nitrogen oxides and for comparison with the GRI-MECH 3.0 (G) method.
The next charts show the max value of the NO concentration for three methods of determining the speed factor of reaction and for comparative for empirical research for seven different the crankshaft rotational speed.

It can be observed that the concentration of $\mathrm{NO}$ determined by authors is the closest to the results of NO concentration in empirical studies. Therefore, it can be assumed that the determination of the NO concentration by authors (S) method is the best way to show the actual NO concentrations in the combustion engine powered by UCOME fuel and other higher-generations fuels with similar physical and chemical properties to UCOME.

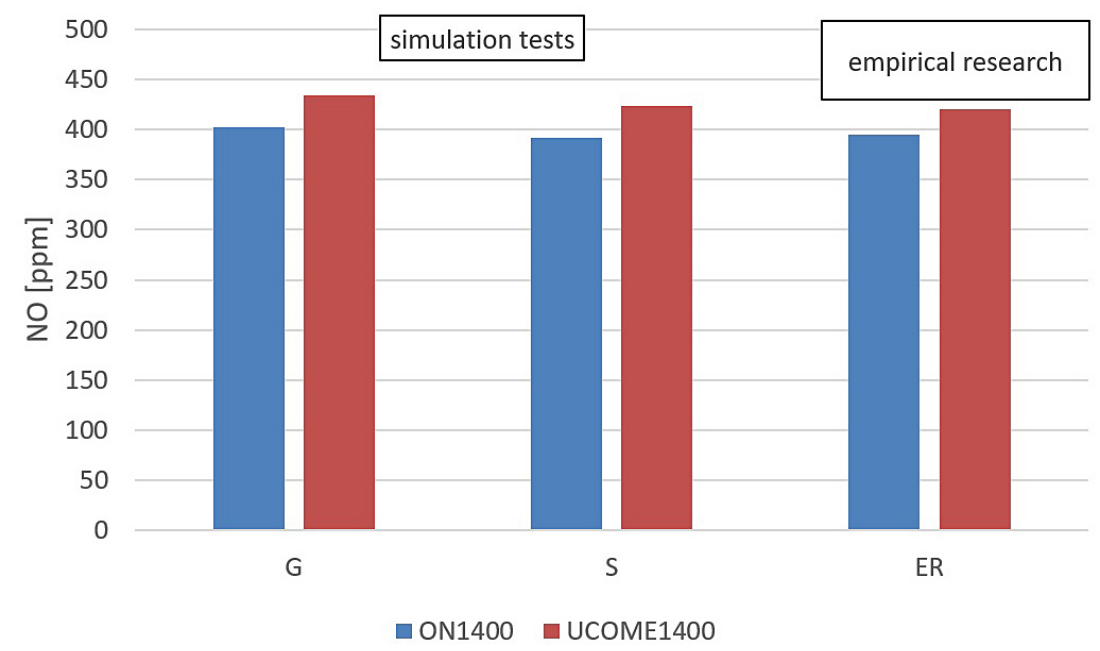

Figure 1. The NO concentration for two methods of determining the coefficient of response speed: GRI-MECH 3.0 (G), Sikora (S) and empirical research for the crankshaft rotational speed $\mathrm{n}=1400 \mathrm{rpm}$ for diesel oil and UCOME fuel

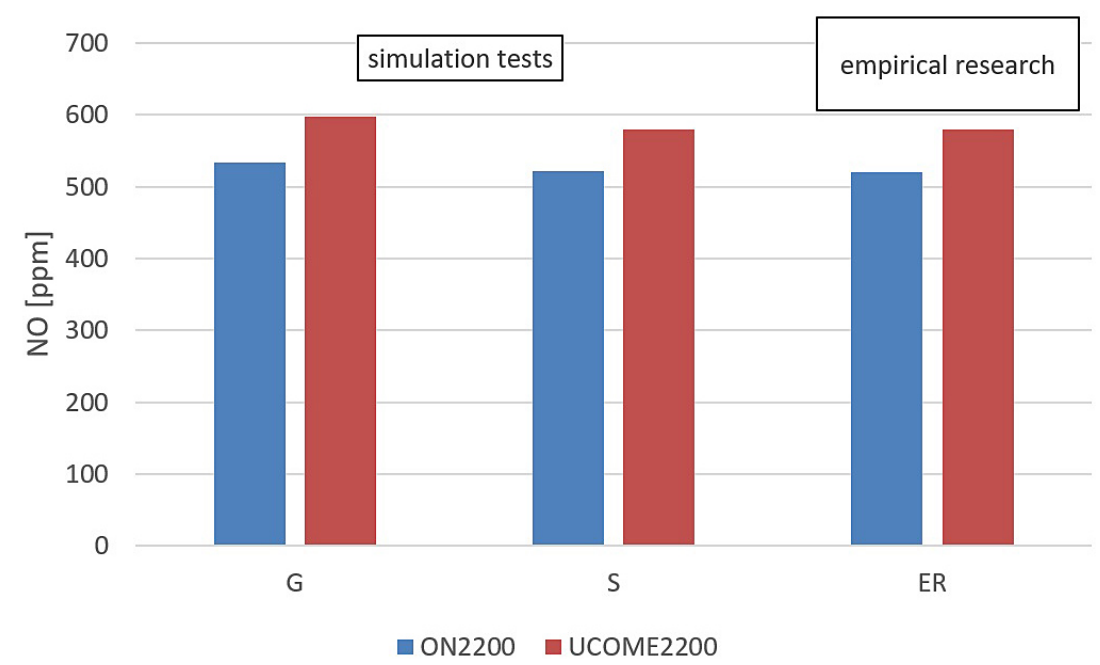

Figure 2. The NO concentration for two methods of determining the coefficient of response speed: GRI-MECH $3.0(\mathrm{G})$, Sikora (S) and empirical research for the crankshaft rotational speed $\mathrm{n}=2200 \mathrm{rpm}$ for diesel oil and UCOME fuel 


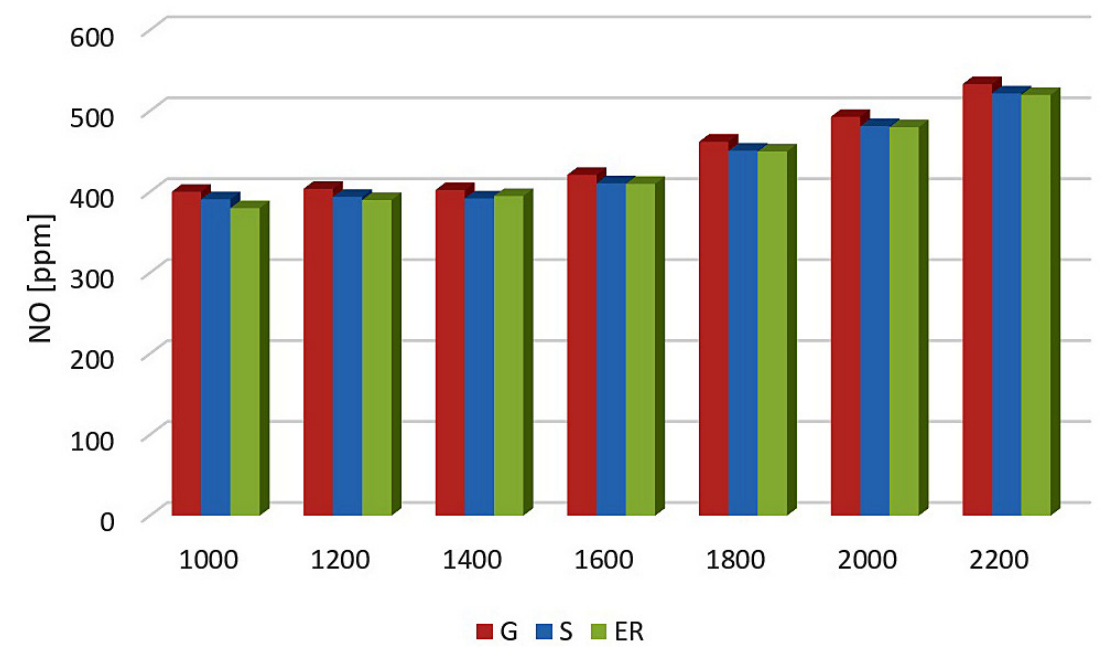

Figure 3. The NO concentration for two methods of determining the coefficient of response speed: GRI-MECH 3.0 (G), Sikora (S) and empirical research for seven different the crankshaft rotational speed for diesel oil

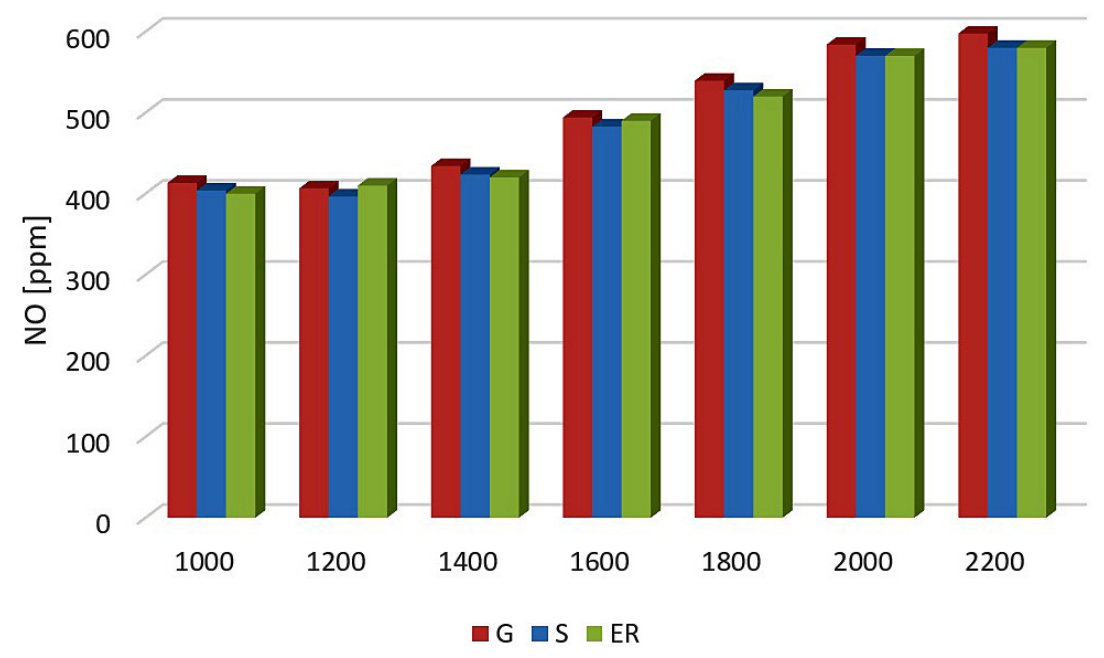

Figure 4. The NO concentration for two methods of determining the coefficient of response speed: GRI-MECH $3.0(\mathrm{G})$, Sikora (S) and empirical research for seven different the crankshaft rotational speed for UCOME fuel

\section{DISCUSSION}

Although there are many methods to determine the concentration of nitrogen oxides, there are no comparative studies of methods for alternative fuels $[9,15,17]$. This paper uses previous studies to determine which method gives the most similar results to the real ones. On the basis of the selected method, it was proposed to select the reaction rate coefficients of nitrogen oxides formation for the engine powered by alternative fuel. An innovative aspect of these studies is the development of a theoretical method for determining oxides dedicated specifically for alternative fuels. Simulation studies have provided a characterization of the oxides of nitrogen concentrations. The NO concentrations determined by (S) method are closest to the results of empirical tests. The difference is about 1-2\% (Figure $3-4)$. The results of simulation tests obtained by GRI-MECH 3.0 (G) show NO concentrations 5\% higher than the results of empirical tests (Figure 3-4). The NO concentration for GRI-MECH 3.0 (G) method determining the reaction velocity factor for UCOME fuel is about $8 \%$ higher than the NO concentration for the same method determining the reaction velocity factor for diesel (Figure 1). The concentration of nitrogen oxides for the authors method (S) of determining the reaction velocity factor for UCOME fuel is about $4-5 \%$ higher than the NO concentration for the same method of determining the reaction velocity factor for diesel (Figure 1-2). The results show that the NO concentration for Sikora (S) 
method increases with the increase of crankshaft rotational speed (Figure 3-4). It should be noted that a similar situation occurs with method GRIMECH $3.0(\mathrm{G})$. For each method the maximum value of nitrogen oxide concentration is the highest for UCOME fuel (Figure 4) for crankshaft speed $n=2200 \mathrm{rpm}$. The maximum value of nitrogen oxide concentration is the lowest for diesel (Figure 3) for crankshaft speed $n=1000 \mathrm{rpm}$. The results are influenced by the physicochemical properties of fuels. This increase in nitrogen oxides concentration was caused by an increase in temperature of the working medium during the combustion process. This was influenced by the elemental composition of the plant-based fuels used. The kinematic viscosity of diesel is twice lower than the kinematic viscosity of UCOME fuel (Table 2). Density of diesel fuel at $288 \mathrm{~K}$ is about 5\% lower than that of UCOME fuel at $288 \mathrm{~K}$ (Table 2). The cetane number of diesel fuel is about $16 \%$ higher than the cetane number of UCOME fuel (Table 2). The research shows that the authors (S) method is an ideal method for testing FAME fuels. The difference is about $2-5 \%$. With the increasing share of alternative fuels in the fuel market, it is recommended to increase the intensity of research on FAME fuels. Therefore, in the following articles we will be testing other FAME esters and diesel with FAME esters. Detailed research on exhaust emissions is necessary and will be carried out in future works.

\section{CONCLUSIONS}

If the engine is powered by diesel fuel, the use of reaction rate coefficients according to the GRIMECH 3.0 method represent the actual nitrogen oxide concentrations very well. The simulation test results obtained with the GRI-MECH 3.0 (G) method show NO concentrations 5\% higher than the empirical test results. The research in this work shows that the G method needs to be corrected when alternative fuels are tested. For UCOME fuel, the simulation test results obtained by GRI-MECH 3.0 (G) method show NO concentrations $8 \%$ higher than the empirical test results.

The method proposed by the authors of the paper allows determining the concentration of nitrogen oxides from a compression ignition engine fueled with liquid alternative fuels. The NO concentrations determined by authors method (S) are the most similar to the results of empirical tests.
The difference is about $1-2 \%$. It will allow the selection of appropriate alternative fuels already at the stage of simulation studies, which will significantly reduce the cost of such studies.

\section{REFERENCES}

1. Choudhary AK., Chelladurai H., Kannan C. Performance analysis of bioethanol (Water Hyacinth) on diesel engine. International Journal of Green Energy. 2016; 13: 1369-1379.

2. Bielaszyc P., Gandyka M., Joseph W., et al. Ethanol as an automotive fuel-a review. Combustion Engines. 2016; 166: 39-45.

3. Kruczyński S., Gis W., Orliński P., et al. Influence of the use of ethanol fuel on selected parameters of the gasoline engine. IOP Conference Series: Materials Science and Engineering. 2018; 421: 042041.

4. Heywood JB. Internal combustion engine fundamentals. McGraw-Hill, 1988.

5. Liati A., Schreiber D., Alpert PA., et al. Aircraft soot from conventional fuels and biofuels during ground idle and climb-out conditions: Electron microscopy and X-ray micro-spectroscopy. Environmental Pollution. 2019; 658-667.

6. Owczuk M., Matuszewska A., Wojs MK., et al. The effect of fuel type used in the spark-ignition engine on the chemical composition of exhaust gases. Przemysl Chemiczny. 2018; 97: 1910-1915.

7. Lasocki J., Bednarski M., Sikora M. Simulation of ammonia combustion in dual-fuel compressionignition engine. IOP Conference Series: Earth and Environmental Science. 2019; 214: 012081.

8. Kruczyński S., Orliński P., Biernat K. Camelina oil as a biofuel for diesel engines. Przemysł Chemiczny. 2012; 91: 111-114.

9. Chuah LF., Aziz ARA., Yusup S., et al. Performance and emission of diesel engine fuelled by waste cooking oil methyl ester derived from palm olein using hydrodynamic cavitation. Clean Technologies and Environmental Policy. 2015; 17: 2229-2241.

10. Valente OS., Pasa VMD., Belchior CRP., et al. Physical-chemical properties of waste cooking oil biodiesel and castor oil biodiesel blends. Fuel. 2011; 90: 1700-1702.

11. Sankar G., Ganesh B., Karu R. Experimental investigations on direct injection diesel engines using grape seed oil methyl ester with different bowl geometries. International Journal of Green Energy. 2019; 16: 590-597.

12. Bednarski M., Orliński P., Wojs MK., et al. Evaluation of methods for determining the combustion ignition delay in a diesel engine powered by liquid biofuel. Journal of the Energy Institute. 2018. 
13. Bednarski M., Samoilenko D., Orliński P., et al. Evaluation of the diesel engine parameters after regeneration of its fuel delivery system. Transport Means - Proceedings of the International Conference; 2017.

14. Flynn PF., Hunter GL., Farrel L., et al. The inevitability of engine-out NOx emissions from spark-ignited and diesel engines. Proceedings of the Combustion Institute. 2000; 28: 1211-1218.

15. Brückner C., Kyrtatos P., Boulouchos K. NOx emissions in direct injection diesel engines: Part 2: model performance for conventional, prolonged ignition delay, and premixed charge compression ignition operating conditions. International Journal of Engine Research. 2018; 19: 528-541.

16. Bueschke W., Wisłocki K., Pielecha I., et al. Influence of the distance between gas injector and intake valve on combustion indicators and NOx emission in dual fuel ci engine. Journal of Mechanical and Transport Engineering. 2017; 69: 5-13.

17. Merker G., Otto F., Schwarz C., et al. Simulating combustion and pollutant formation for enginedevelopment. Springer, 2006.

18. Sindhu R., Amba Prasad Rao G., Madhu Murthy K. Effective reduction of NOx emissions from diesel engine using split injections. Alexandria Engineering Journal. 2018; 57: 1379-1392.

19. Kruczyński P., Orliński P., Kamela W., et al. Analysis of selected toxic components in the exhaust gases of a CI engine supplied with water-fuel emulsion. Polish Journal of Environmental Studies. 2018; 27: 129-136.

20. Longhurst J. Air Pollution XXII: Twenty Second Conference on Modelling, Monitoring and Management of Air Pollution. 183.

21. Krakowian K., Kamierczak A., Wdowikowska A. Modern diesel engines NOx particles emission. 2013.

22. Martínez-Morales JD., Palacios E., Carrillo GAV. Modeling of internal combustion engine emissions by LOLIMOT algorithm. Procedia Technology. 2012; 3: 251-258.

23. Kumar M., Tsujimura T., Suzuki Y. NOx model development and validation with diesel and hydrogen/diesel dual-fuel system on diesel engine. Energy. 2018; 145: 496-506.

24. Luo Q he., Hu J Bin., Sun B gang., et al. Experimental investigation of combustion characteristics and NOx emission of a turbocharged hydrogen internal combustion engine. International Journal of Hydrogen Energy. 2019; 5573-5584.

25. Ziółkowska M. Wpływ paliw estrowych na procesy utleniania oleju silnikowego w czasie eksploatacji. Nafta-Gaz. 2017; 73: 43-48.

26. Kumar KV., Prasad VVS. Production and characterization of used cooking oil as an alternative fuel: optimization by response surface methodology. Mathematical Models in Engineering. 2018; 4: 18-28. 
